\title{
Air Flow Regimes and Thermal Comfort in Vehicle Cabin Considering Solar Radiation
}

\author{
Ibrahim Reda ${ }^{1}$, Essam E Khalil2*, Taher M Aboudeif ${ }^{2}$ and Ahmed El Degwy ${ }^{2}$
}

${ }^{1}$ Department of Mechanical Power, Faculty of Engineering, Cairo University, Egypt

${ }^{2}$ Arab HVAC Code Committee ASHRAE Director-At-Large, USA and Convenor ISO TC205 WG2, Co-Convenor ISO TC163 WG4, Deputy Director (International) AIAA, USA

\begin{abstract}
Thermal comfort in vehicle cabin can affect drivers and passenger's health, performance and comfort. Due to spatial and temporal variation of state variables and boundary conditions in the vehicle cabin, the heating, ventilating and airconditioning (HVAC) does not have to be designed to provide a uniform environment, especially because of individual differences regarding to physiological and psychological response, clothing insulation, activity, air temperature and air movement preference, etc. The main objective of this research is to study the air flow regimes and thermal comfort in vehicle cabin using computational fluid dynamics (CFD) software. For this purpose, the CFD software from ANSYS Inc., called FLUENT 17.2, is employed. In which the solar load model is embedded s2s (surface to surface) as a solar radiation model. The CFD modeling techniques solved the continuity, momentum and energy conservation equations in addition to standard $k-\varepsilon$ model equations for turbulence closure (The use K-epsilon turbulence mode was recommended as it had been widely tested and investigated in the seventies of last century). Meshing is processed around 4.0 million unstructured tetra-elements approximately. The performance of the air conditioning system is characterized by airflow regimes (air temperature, air velocity, relative humidity, PMV and PPD contours), the present work is focus on the effect of air terminal shape of Hvac system, two configurations are used case (1) and case (2). Case (1) is the existing design of air terminals of the Hvac system of the selected car (Skoda Superb), the air terminals are in rectangular shape, while case (2) is in circle shape.
\end{abstract}

Keywords: Computer fluid dynamics (CFD); Air flow regimes; Thermal comfort; Predicted mean vote (PMV); Predicted percentage dissatisfied (PPD)

\section{Introduction}

As vehicles become an indispensable part of everyday life, people spend 1-10 hours each day in vehicle [1]. Therefore the thermal comfort of passengers draws more and more attention. Lately, High levels of vehicle comfort are being increasingly demanded by users, this creates a new challenge for climate control engineers. In the past, it typically took a year to develop and fully characterise the Heating, Ventilation and Air-Conditioning (HVAC) system for a new model vehicle using conventional physical testing methods. However, the use of computational fluid dynamics (CFD) simulators can dramatically reduce time of development of automotive HVAC systems, contribute to improvement of their performance and provide better understanding of the underlying processes. Thermal comfort not only affects the energy consumption of the HVAC system, but is also a key parameter for passenger health. It contributes to safe driving by reducing the driver stress, avoiding windshield fogging, and guaranteeing good visibility. Comfortable climate is usually defined as "the condition of mind that expresses satisfaction with the thermal environment" [2]. The human climate experience is essentially an interaction between six parameters, air temperature, mean radiant temperature, relative air movements, air humidity, activity level and thermal properties of clothing and seat. It is also possible to further divide the physical comfort sensation in two categories, local and whole body thermal comfort. The whole body value only consists of a mean value, while the local values takes into consideration effects on different body parts.

\section{Numerical Model Description}

A Car model was chosen for present analysis is "Skoda-Superb", the blueprints of the geometry is available on the web for any person easily to find, the geometry of the cabin was constructed using
Solidworks v.17 software (Figure 1). The compartment was modelled as $1.5 \mathrm{~m} \times 1.2 \mathrm{~m} \times 3.0 \mathrm{~m}, \mathrm{x}, \mathrm{y}, \mathrm{z}$ respectively, further a several features are added to the model to make it ready to mesh in Fluent 17.2, four passengers are added to the model, the interior volume of the vehicle cabin was estimated to be $2.6 \mathrm{~m}^{3}$.The total glass surface area including the windshield and the side and rear glasses, was estimated to be $3.2 \mathrm{~m}^{2}$. Heat Transfer by radiation is considered from all car cabin windows and here we use P1 model.

Figure 2 illustrates the computational model of the cabin (ANSYS
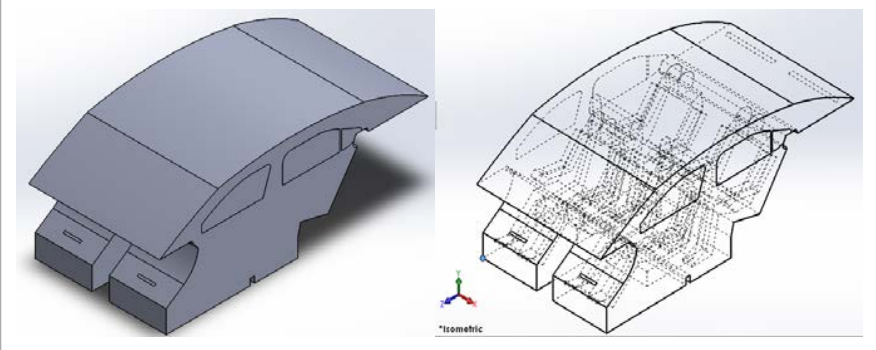

Figure 1: Vehicle cabin complex geometry (Solidworks v.17).

*Corresponding author: Khalil EE, PhD London, Chairman Arab HVAC Code Committee ASHRAE Director-At-Large, USA, Convenor ISO TC205 WG2, CoConvenor ISO TC163 WG4, Deputy Director (International) AIAA, USA, Tel: +20122-2116611/+1-202-3860163; Fax: +20-2-33362433; E-mail: khalile1@asme.org

Received May 20, 2017; Accepted August 15, 2017; Published August 25, 2017

Citation: Reda I, Khalil EE, Aboudeif TM, Degwy AE (2017) Air Flow Regimes and Thermal Comfort in Vehicle Cabin Considering Solar Radiation. Fluid Mech Open Acc 4: 174. doi: 10.4172/2476-2296.1000174

Copyright: (c) 2017 Reda I, et al. This is an open-access article distributed under the terms of the Creative Commons Attribution License, which permits unrestricted use, distribution, and reproduction in any medium, provided the original author and source are credited. 
Citation: Reda I, Khalil EE, Aboudeif TM, Degwy AE (2017) Air Flow Regimes and Thermal Comfort in Vehicle Cabin Considering Solar Radiation. Fluid Mech Open Acc 4: 174. doi: 10.4172/2476-2296.1000174

Page 2 of 7

17.2) in case one with 14 supply inlets and 2 return outlets air terminals. Four inlets were located on the front dashboard: one on the driver's left side $\left(A_{1}\right)$, one on the co-pilot's right side $\left(A_{2}\right)$, and two in the center $\left(B_{1}, B_{2}\right)$. Two inlets to maintain defrost $\left(C_{1}, C_{2}\right)$ where the windshield met the front dashboard. Two inlets to supply air to each side window $\left(D_{1}, D_{2}\right)$. Another two inlets serving the rear passengers $\left(G_{1}, G_{2}\right)$. The remaining four inlets were located in the leg space of the four passengers $\left(\mathrm{E}_{1}-\mathrm{E}_{4}, \mathrm{~F}_{1}-\mathrm{F}_{4}, \mathrm{H} 1-\mathrm{H}_{4}\right.$, and I1- $\left.\mathrm{I}_{4}\right)$. Two outlet vents $\left(\mathrm{M}_{1}\right)$ were located at the rear board of the passenger compartment, where the rear window met the rear board [3].

\section{Case Studies}

\section{Case (1) modeling}

Configuration: Figure 3 shows the geometry (1) for the cabin which is already exists in the vehicle "Skoda Superb", 14 supply (white) inlets, and 2 return (red) outlets. All the outlets are in rectangular shape.
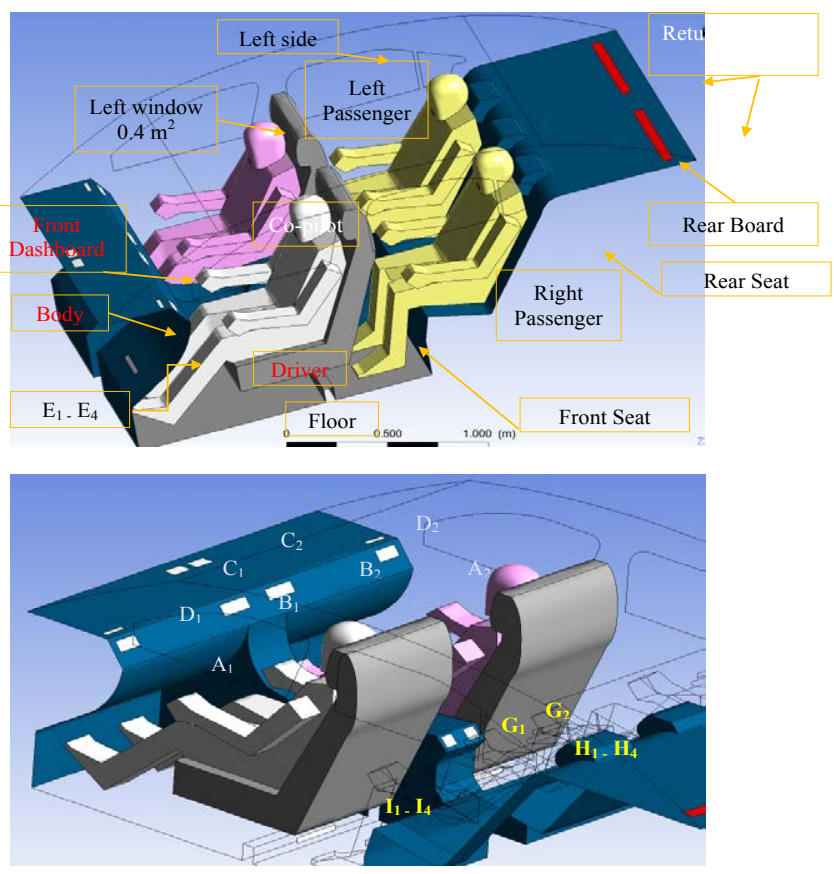

Figure 2: Vehicle cabin complex geometry (Ansys 17.2).

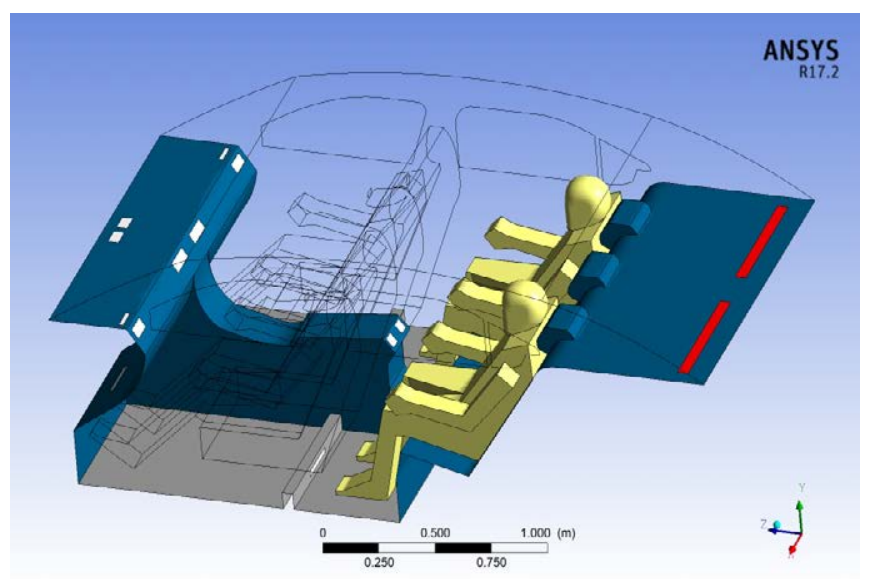

Figure 3: Geometrical configuration of Case (1)

\section{Boundary conditions}

a. Joo Hyun Moon et al. [4] considered velocity inlet is $3.27 \mathrm{~m} / \mathrm{s}$ inside the compartment.

b. Han and Huang [5] suggested Passenger thermal load will be considered as a heat flux $80 \mathrm{w} / \mathrm{m}^{2}$.

c. ASHRAE realistic method for calculating the direct and diffuse solar irradiation on the earth's surface is applied for Cairo (latitude $30.05^{\circ}$ degree) at $13.00 \mathrm{PM}$ in 21 June while windshield tilted $30^{\circ}$ degree facing south (surface azimuth angle equal zero, maximum solar heat gain), and the altitude angle is $75^{\circ}$ degree, Solar irradiation of $970 \mathrm{~W} / \mathrm{m}^{2}$ was specified. The normal direct irradiation will be $880 \mathrm{~W} / \mathrm{m}^{2}$, and the diffused solar irradiation will be $110 \mathrm{~W} / \mathrm{m}^{2}$.

d. The emissivity for interior surfaces equals 0.95 surfaces [6] and for glass equals 0.88 [7].

e. Human body and properties of material specified in (Table 1).

f. Inlet temperature is $12^{\circ} \mathrm{C}[8]$.

\section{Case (2) modeling}

Configuration: Figure 4 shows the geometry (2) which is planned for comparison purpose of the vehicle cabin geometry, 14 supply (white) inlets, and 3 return (red) outlets; all the outlets are in circle shape equal to the total area of the rectangular shape in geometry (1).

Boundary conditions: All boundary conditions are copied from case one.

\section{Results and Discussion}

\section{Temperature contours}

Figure 5 shows the temperature distribution around the

\begin{tabular}{|c|c|c|c|c|}
\hline & Material & $\begin{array}{l}\text { Density } \\
\left(\mathbf{k g ~ m}^{-3}\right)\end{array}$ & $\begin{array}{c}\text { Specific } \\
\text { heat }\left(\mathrm{J} \mathrm{kg}^{-1}\right. \\
\left.\mathrm{K}^{-1}\right)\end{array}$ & $\begin{array}{c}\text { Thermal } \\
\text { conductivity } \\
\left(\mathrm{W} \mathrm{m}^{-2} \mathrm{~K}^{-1}\right)\end{array}$ \\
\hline $\begin{array}{l}\text { Windshield, rear, } \\
\text { side glass }\end{array}$ & Glass & 2529.58 & 754.04 & 1.1717 \\
\hline $\begin{array}{l}\text { Body, dashboard, } \\
\text { rear board }\end{array}$ & ABS plastic & 996.35 & 1480.60 & 2.70 \\
\hline Seat & $\begin{array}{l}\text { Polyurethane } \\
\text { foam }\end{array}$ & 70.00 & 1685.60 & 0.05 \\
\hline Floor & Carpet & 1601.85 & 1485.38 & 0.2942 \\
\hline Driver & Skin & 1000 & 3770 & 0.21 \\
\hline
\end{tabular}

Table 1: Human body and properties of material.

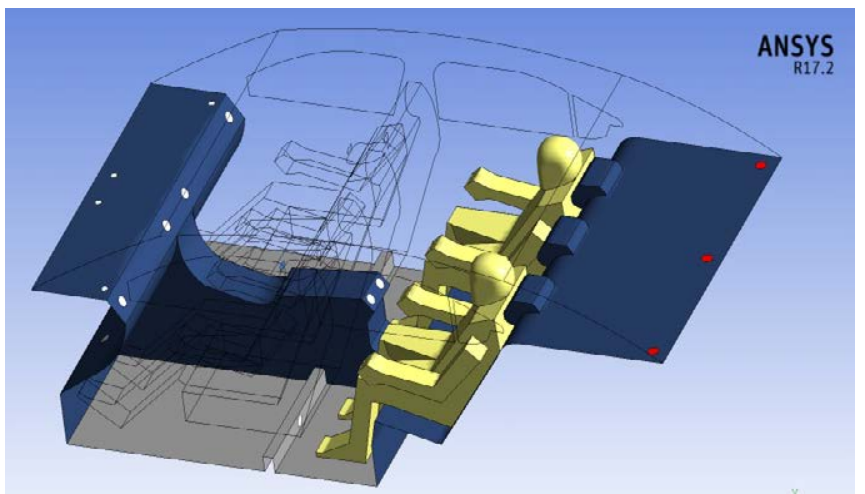

Figure 4: Geometrical configuration of Case (2). 
Citation: Reda I, Khalil EE, Aboudeif TM, Degwy AE (2017) Air Flow Regimes and Thermal Comfort in Vehicle Cabin Considering Solar Radiation. Fluid Mech Open Acc 4: 174. doi: 10.4172/2476-2296.1000174

passengers' head of case (1), the simulations shows that temperature becomes approximately 26-30 degree Celsius around driver and copilot, while it becomes approximately 26-28 degree Celsius around rear passenger head. Figure 5 shows the temperature distribution around the passengers' head of case (2), temperature becomes approximately 32-34 degree Celsius around driver and co-pilot, while it becomes approximately 28-30 degree Celsius around rear passenger head. The temperature between the cabin side walls and the passengers are relatively high due to the skin temperature of the passenger and the effect of solar radiation. Figure 6 shows that temperature becomes approximately 30-34 degree Celsius around driver and co-pilot chest of case (1), while it becomes approximately 26-28 degree Celsius around rear passenger chest. Figure 6 shows that temperature becomes approximately 34-36 degree Celsius around driver and co-pilot chest of case (2), while it becomes approximately 30-32 degree Celsius around rear passenger chest.

Figure 7 shows that temperature becomes approximately 26-30 degree Celsius around all passengers knee of case (1). Figure 7 shows that temperature becomes approximately 34-36 degree Celsius around all passengers knee of case (2). Figure 8 shows that temperature becomes approximately 26-28 degree Celsius around driver and copilot foot of case (1), while it becomes approximately 28-30 degree Celsius around rear passenger foot. Figure 8 shows that temperature becomes approximately 30-32 degree Celsius around driver and copilot foot of case (2), while it becomes approximately 32-34 degree Celsius around rear passenger foot.

Figure 9 shows the velocity distribution around the passengers' head of case (1), the simulations shows that velocity becomes approximately $0.6 \mathrm{~m} / \mathrm{s}$ around driver and co-pilot head, while it becomes approximately $0.7 \mathrm{~m} / \mathrm{s}$ around rear passenger head. Figure 9 shows the velocity
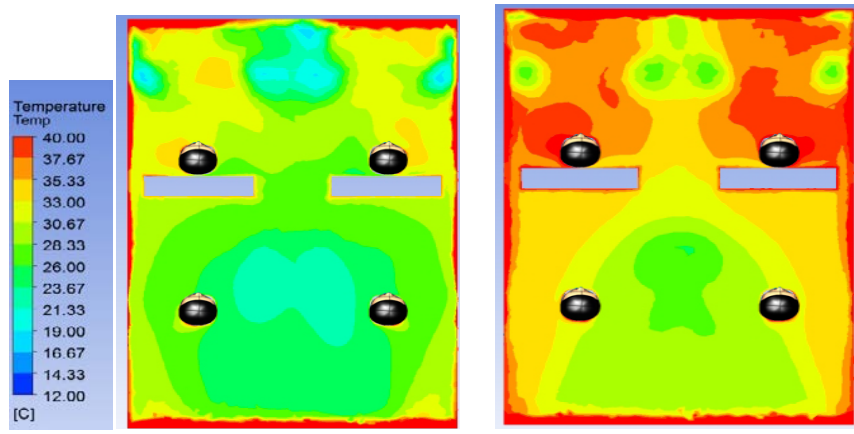

Figure 5: (Case 1 and 2) Temperature Contour at horizontal at $\mathrm{Y}=0.9 \mathrm{~m}$ (Head level).

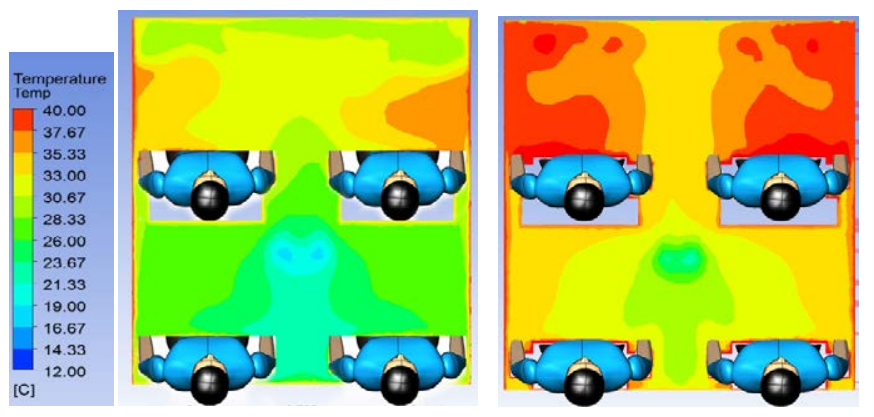

Figure 6: (Case 1 and 2) Temperature Contour at horizontal plane (ZX) at $\mathrm{Y}=0.7 \mathrm{~m}$ (Chest level).

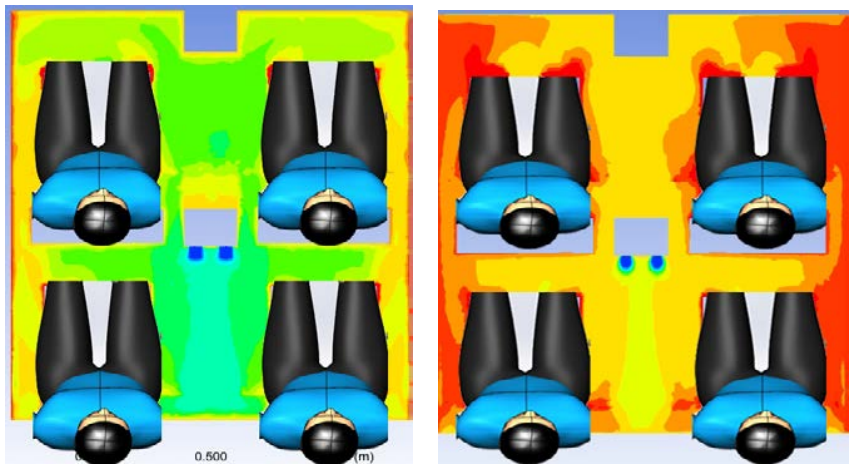

Figure 7: (Case 1 and 2) Temperature Contour at horizontal plane (ZX) at $\mathrm{Y}=0.45 \mathrm{~m}$ (Knee level)

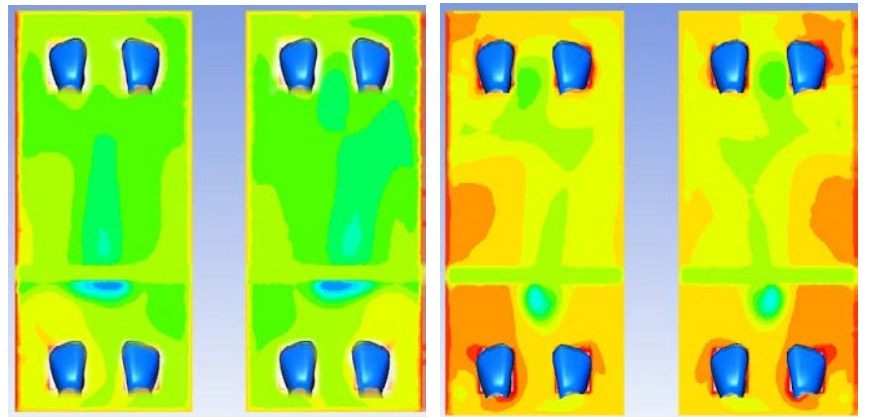

Figure 8: (Case 1 and 2) Temperature Contour at horizontal plane (ZX) at $\mathrm{Y}=0.13 \mathrm{~m}$ (Foot level).
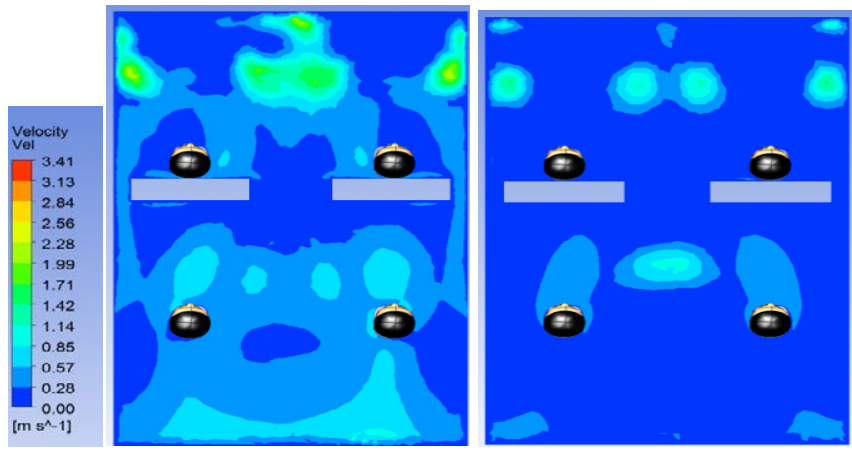

Figure 9: (Case 1 and 2) Temperature Contour at horizontal plane (ZX) at $\mathrm{Y}=0.9 \mathrm{~m}$ (Head level).

distribution around the passengers' head of case (2), velocity becomes approximately $0.25 \mathrm{~m} / \mathrm{s}$ around driver and co-pilot head, while it becomes approximately $0.5 \mathrm{~m} / \mathrm{s}$ around rear passenger head. Figure 10 shows that velocity becomes approximately $0.3 \mathrm{~m} / \mathrm{s}$ around driver and co-pilot chest of case (1), while it becomes approximately $0.7 \mathrm{~m} / \mathrm{s}$ around rear passenger chest. Figure 10 shows that velocity becomes approximately $0.25 \mathrm{~m} / \mathrm{s}$ around driver and co-pilot chest of case (2), while it becomes approximately $0.5 \mathrm{~m} / \mathrm{s}$ around rear passenger chest. Figure 11 shows that velocity becomes approximately $0.7 \mathrm{~m} / \mathrm{s}$ around all passengers knee of case (1). Figure 11 shows that velocity becomes approximately $0.25 \mathrm{~m} / \mathrm{s}$ around driver and co-pilot knee of case (2), while it becomes approximately 0.5 around rear passenger knee.

Figures 12 shows that velocity becomes approximately $0.25 \mathrm{~m} / \mathrm{s}$ 
Citation: Reda I, Khalil EE, Aboudeif TM, Degwy AE (2017) Air Flow Regimes and Thermal Comfort in Vehicle Cabin Considering Solar Radiation. Fluid Mech Open Acc 4: 174. doi: 10.4172/2476-2296.1000174

Page 4 of 7
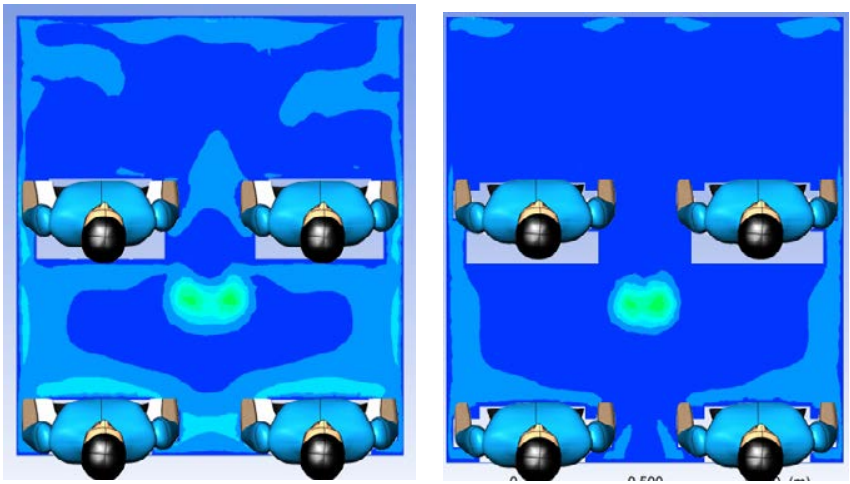

Figure 10: (Case 1 and 2) Temperature Contour at horizontal plane $(Z X)$ at $Y=0.7 \mathrm{~m}$ (Chest level)
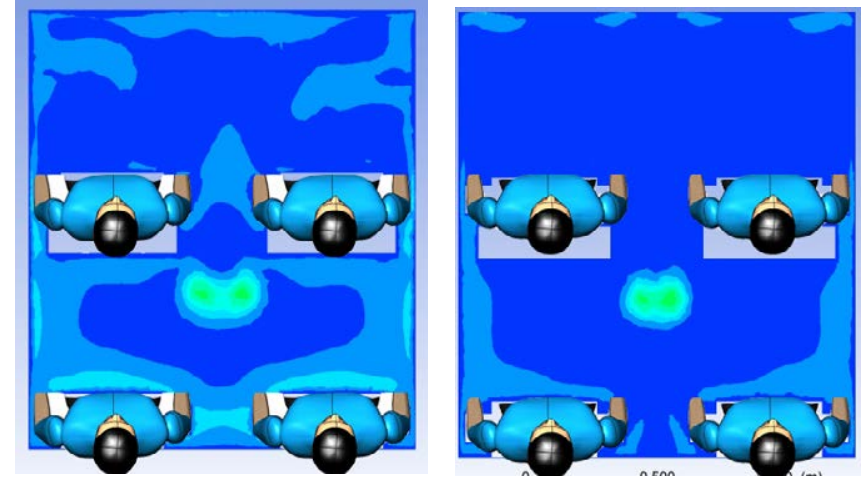

Figure 11: (Case 1 and 2) Temperature Contour at horizontal Plane $(Z X)$ at $Y=0.45 \mathrm{~m}$ (Knee level).
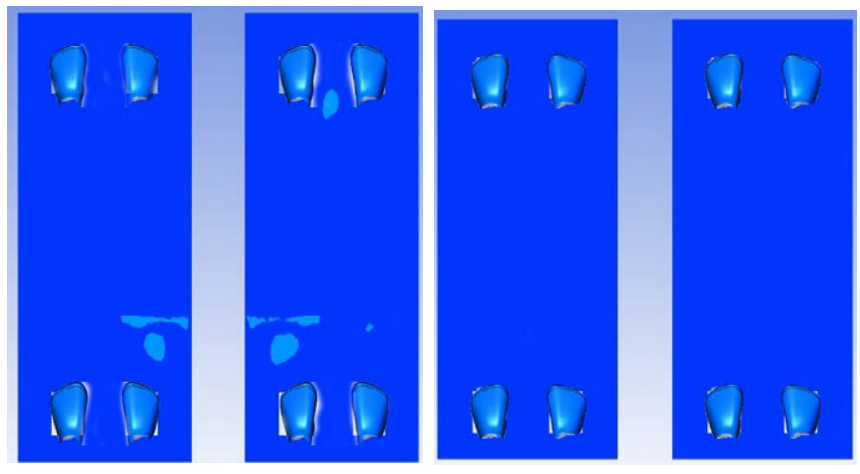

Figure 12: (Case 1 and 2) Temperature Contour at horizontal plane $(\mathrm{ZX})$ at $\mathrm{Y}=0.13 \mathrm{~m}$ (Foot level)

around all passengers foot in case (1) and case (2) respectively. Figure 13 shows the relative humidity distribution inside the cabin at mouth level of case (1), the simulations shows that relative humidity reaches $30 \%$ in the first half of the cabin, while becomes approximately $45 \%$ in the second half. Solar radiation effect appears near to sides of the cabin and windshield, relative humidity not larger than $5 \%$.

Figure 14 shows the relative humidity distribution inside the cabin at mouth level of case (2), the simulations shows that relative humidity reaches $10-20 \%$ in the first half of the cabin, while becomes approximately $25-35 \%$ in the second half. These values reflect the bad agreement of relative humidity distributions due to relatively high temperatures.

\section{Predicted Mean Vote (PMV and Predicted Percentage Dissatisfied (PPD) contours}

Figure 15 shows the PMV contour inside the cabin at mouth level of case (1), the simulations shows a bad distribution (too hot may be reaches to +3 ) in the whole cabin except the middle of cabin in the second half and near to the air inlets in the first half of the cabin, it's value between -0.5 to +0.5 .

Figure 16 shows the PPD contour inside the cabin at mouth level of case (1), the simulations shows a bad distribution near to $100 \%$ dissatisfaction, especially in the left, right sides of the cabin and near 


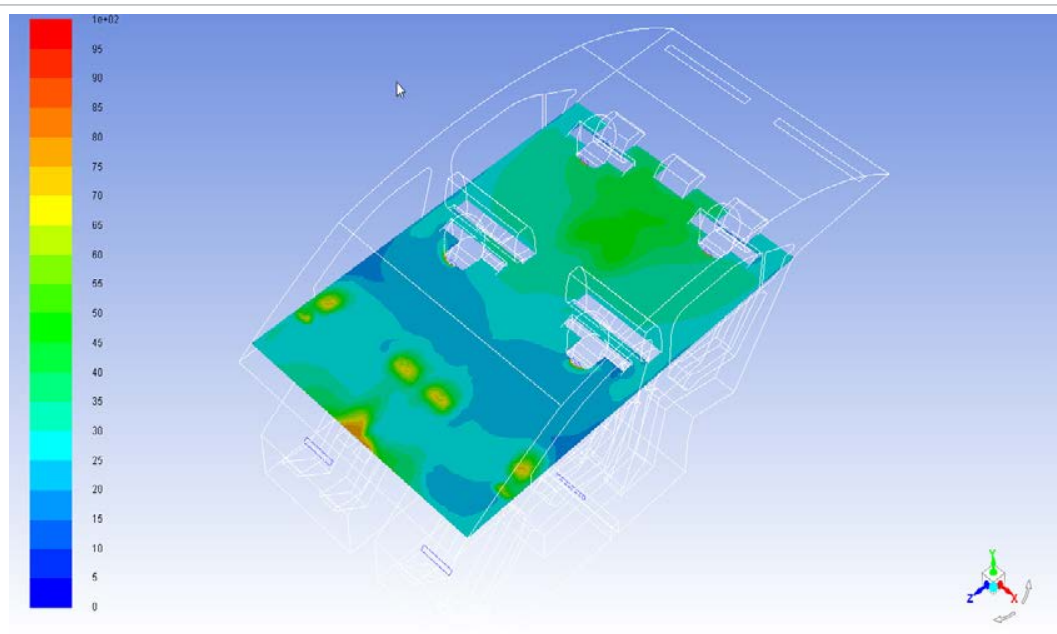

Figure 13: Relative humidity contour at horizontal plane $(Z X)$ at $Y=0.83 \mathrm{~m}$ (Mouth level).

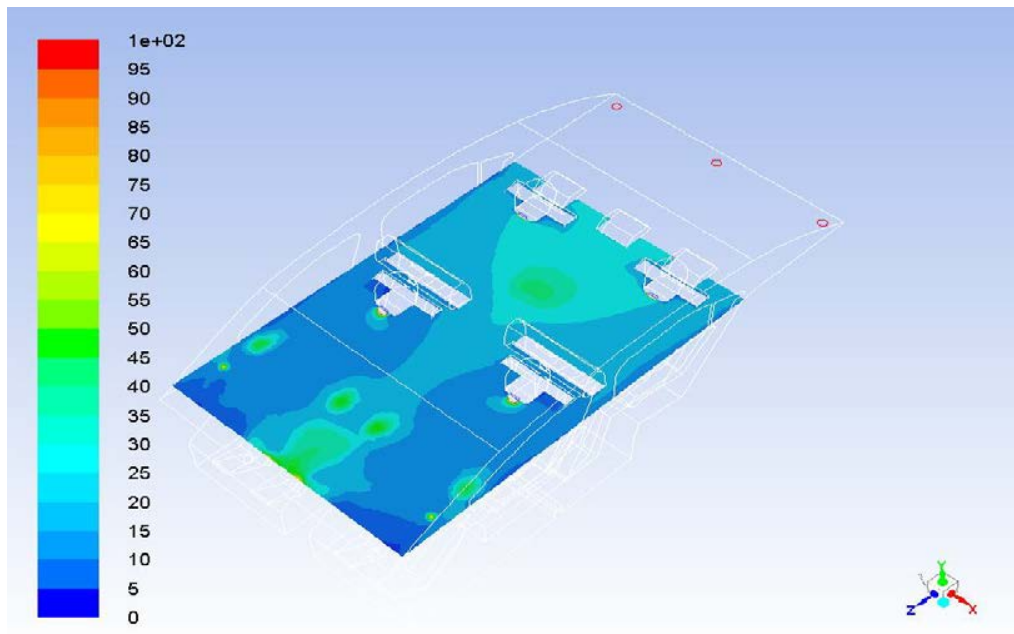

Figure 14: Relative humidity contour at horizontal plane $(Z X)$ at $Y=0.83 \mathrm{~m}$ (Mouth level).

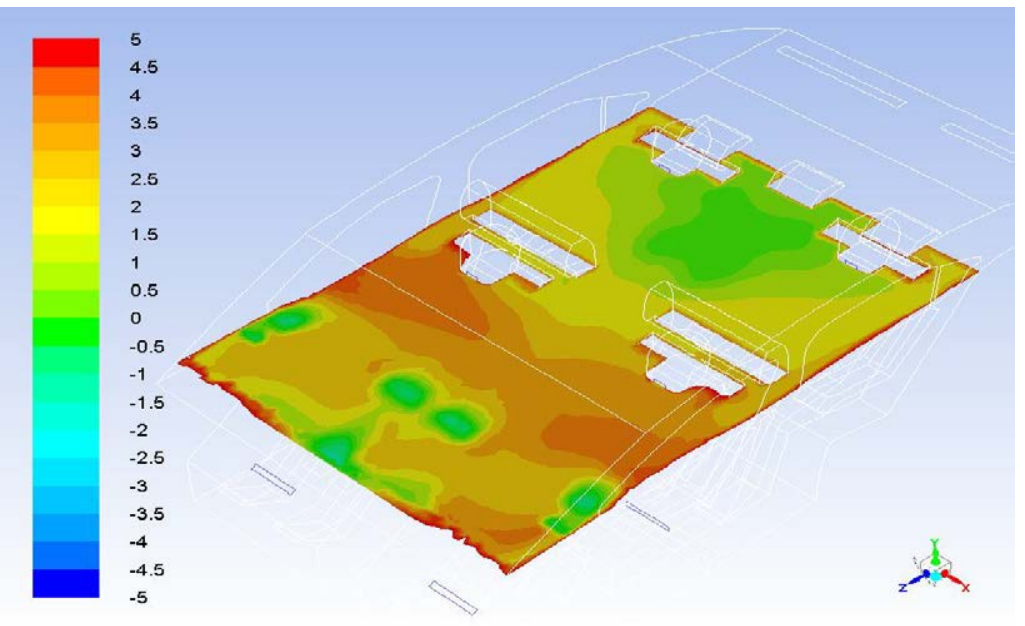

Figure 15: PMV contour at horizontal plane $(Z X)$ at $Y=0.83 \mathrm{~m}$ (Mouth level). 


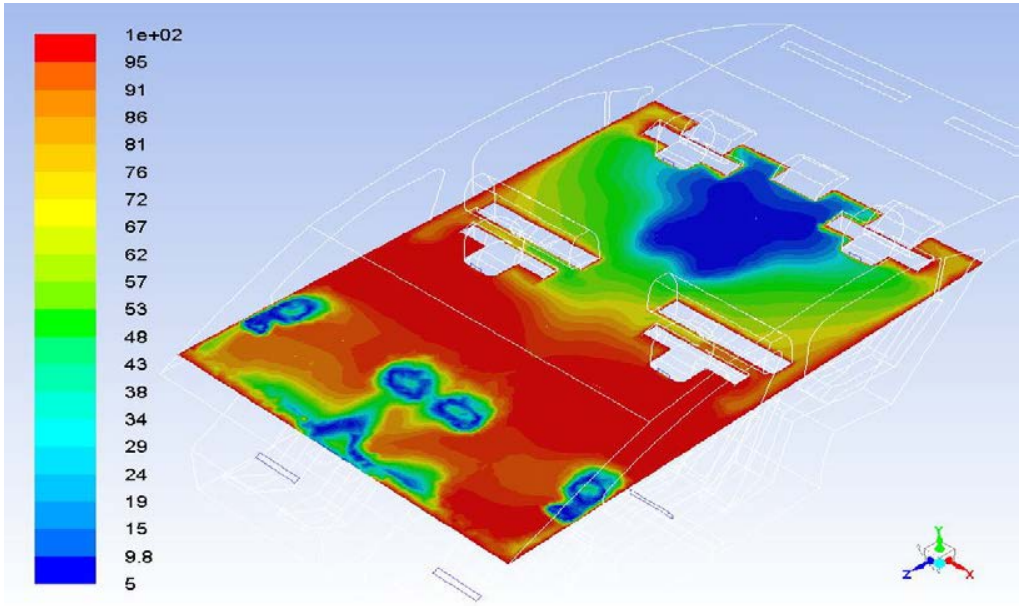

Figure 16: PPD contour at horizontal plane $(Z X)$ at $Y=0.83 \mathrm{~m}$ (Mouth level).

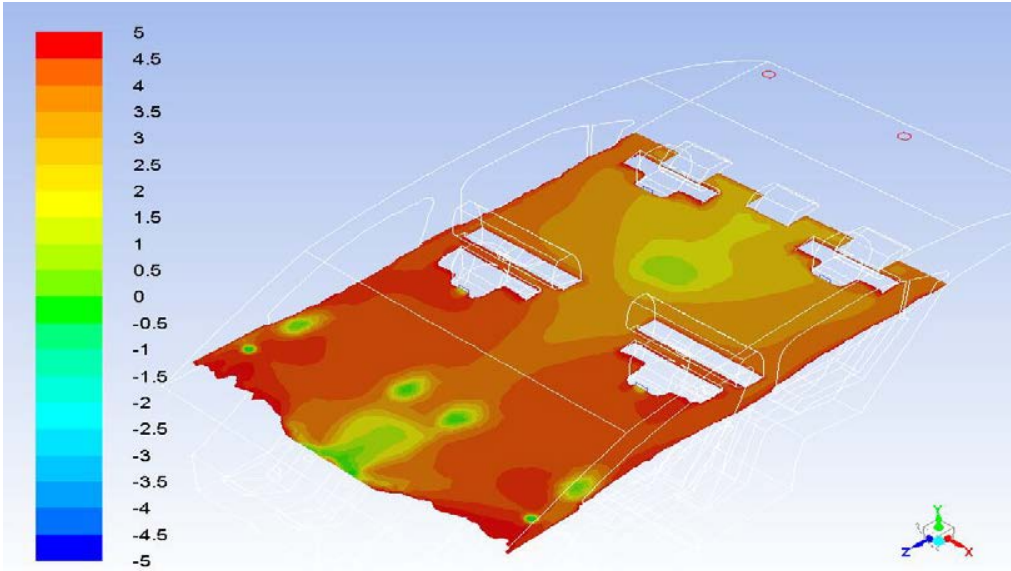

Figure 17: PMV contour at horizontal plane $(Z X)$ at $Y=0.83 \mathrm{~m}$ (Mouth level).

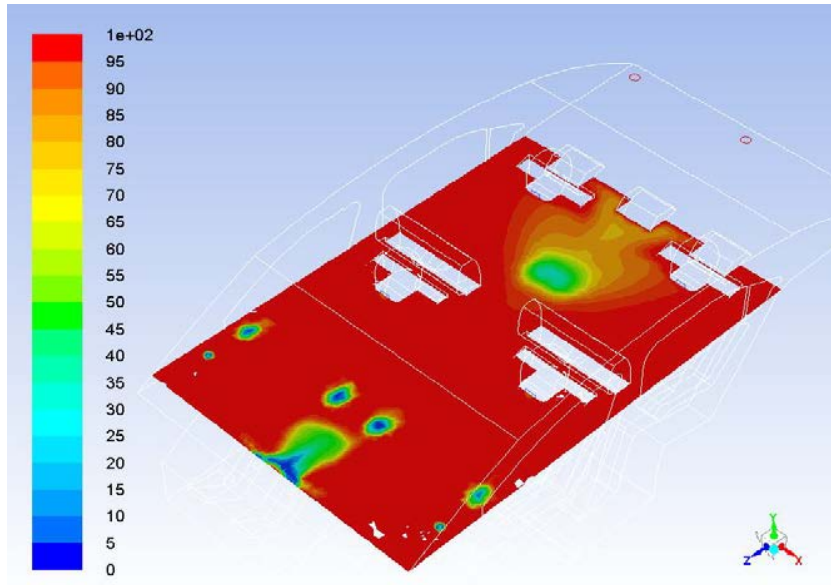

Figure 18: PPD contour at horizontal plane $(Z X)$ at $Y=0.83 \mathrm{~m}$ (Mouth level)

to the windshield due to the effect of solar radiation. The PPD values are affected by the PMV values because the PPD equation is a function of the PMV. The PPD values around the driver and co-pilot's head are about $100 \%$ and around the rear passenger's head are about $50 \%$.
Figure 17 shows the PMV contour inside the cabin at mouth level of case (1), the simulations shows a bad distribution (too hot may be reaches to +3 ) in the whole cabin except the middle of cabin in the 
Citation: Reda I, Khalil EE, Aboudeif TM, Degwy AE (2017) Air Flow Regimes and Thermal Comfort in Vehicle Cabin Considering Solar Radiation. Fluid Mech Open Acc 4: 174. doi: 10.4172/2476-2296.1000174

Page 7 of 7

second half and near to the air inlets in the first half of the cabin, it's value between -0.5 to +0.5 .

Figure 18 shows the PPD contour inside the cabin at mouth level of case (1), the simulations shows a bad distribution near to $100 \%$ dissatisfaction, especially in the left, right sides of the cabin and near to the windshield due to the effect of solar radiation. The PPD values are affected by the PMV values because the PPD equation is a function of the PMV. The PPD values around the driver and co-pilot's head are about $100 \%$ and around the rear passenger's head are about $50 \%$ (for this work we used laptop with I7 core. The software use is Fluent ANSYS that is commercially available, well tested and verified over the past 20 years. With extensive comparisons with experiments, the radiative conditions used are those of Cairo Egypt that could be extracted from any metrological station data.

\section{Conclusions}

According to the results found in previous comparison obtained by using the numerical investigation, the following conclusions can be expressed:

- The air flow regimes obtained by configuration (1) in case (1) which has rectangular shape is better than circular shape found in configuration (2) in case (2).

- The rectangular shape of air terminals of Hvac system of vehicular system is lower with $2-4^{\circ} \mathrm{C}$ when compared with circular shape, while the velocity in circular shape is lower than rectangular.
- Both two cases achieve a bad agreement between the average air velocity and average temperature with the ASHRAE comfort conditions within the occupied zones, the temperature inside the cabin exceeds $26^{\circ} \mathrm{C}$, relative humidity is lower than $50 \%$ in the whole cabin, air velocity is larger than $0.25 \mathrm{~m} / \mathrm{s}$, PMV contour inside the whole cabin is about +3 satisfaction which means too hot feeling and leads to discomfort, and PPD may be reaches $100 \%$ dissatisfaction in a major area inside the cabin.

\section{References}

1. Frank ML Andresen D, Schmidt TL (2004) Obesity relationships with community design, physical activity, and time spent in cars." Am J Prev Med 27: 87-96.

2. ASHRAE (2013) Thermal environmental conditions for human occupancy, ANSI/ASHRAE Standard 55-2013, American Society of Heating, Refrigerating and Air-Conditioning Engineers, Atlanta, GA

3. Fojtlín M, Planka M, Fišer J, Pokorný J, Jícha M (2016) Airflow Measurement of the Car HVAC Unit Using Hot-wire Anemometry, EPJ web of conferences 114

4. Moon JH, Lee JW, Jeong CH, Lee SH (2016) Thermal comfort analysis in a passenger compartment considering the solar radiation effect. International Journal of Thermal Sciences 107: 77-88.

5. Han T, Huang L (2004) A model relating a thermal comfort scale to EHT comfort index. SAE Technical Paper 01: 0919.

6. Fluke 561 (2006) infrared thermometer user manual. USA: Fluke Corporation.

7. Mezrhab A, Bouzidi M (2006) Computation of thermal comfort inside a passenger car compartment. Appl Therm Eng 26: 169-704.

8. Adhikari VP, Nassar A, Nagpurwala QH (2009) Numerical studies on the effect of cooling vent setting and solar radiation on air flow and temperature distribution in a passenger car. SAE Technical Paper 28: 48. 